\title{
OPEN Demirjian and Cameriere methods for age estimation in a Spanish sample of 1386 living subjects
}

\author{
Maria Melo $\mathbb{D}^{1}$, Fadi Ata-Ali $\mathbb{D}^{2}$, Javier Ata-Ali ${ }^{2,3,4,6 \bowtie}$, José María Martinez Gonzalez ${ }^{5}$ \& \\ Teresa Cobo ${ }^{2}$
}

Currently, human identification is a challenge. Migration due to war, economic crisis or other factors is frequent. The wisdom teeth are the last teeth to initiate and complete development therefore, are fundamental for determining the legal age of majority in different countries. The aim of the study is to determine the validity of two methods based on mineralisation of the third molar to predict the ages of majority of individuals in a Spanish population. Orthopantomographies of 636 men and 750 women (mean age, 16.5 years) were analysed. The Demirjian and Cameriere methods were used, and each tooth was assigned a value according to the degree of mineralisation and maturation. The level of significance used in the analyses was $5 \%(\alpha=0.05)$, with a power of $96.2 \%$. The predictive ability of the Demirjian method to determine 18 years of age in the lower wisdom teeth $93 \%$, respectively. The Cameriere method has a predictive capacity of $88 \%$. There are no statistically significant differences between men and women. Stage $\mathrm{H}$ and a cut-off point of 0.08 were the guiding values for determining the age of majority of the study population. For other proposed age ranges (14 and 16 years), both methods were useful in determining the actual age of individuals, with the Demirjian method having a sensitivity of $\mathbf{9 7 . 5 \%}$ with and Cameriere having a predictive capacity of $95 \%$. Both methods can be used with high reliability to determine the age of individuals where reliable documentation is unavailable. Stage $\mathrm{H}$ with the Demirjian method and a cut-off point of 0.08 with the Cameriere method can determine the age of majority of the Spanish population. The combination of the two methods does not substantially increase predictive ability.

The estimation of an individual's age is a necessary procedure in forensic medicine and for various legal matters such as identification of corpses, adoption procedures, illegal immigration, or determining legal liability ${ }^{1-3}$.

Several methods are available for determining the actual age of an individual, including those based on different stages of bone maturation, which have been proposed by different authors such as Fishman ${ }^{4}$, Björk $^{5}$, or Bacetti ${ }^{6}$. However, several studies state that while these methods are useful in understanding growth potential, they are not useful in determining an individual's age $e^{7,8}$. Methods based on the study of teething have proven to be more accurate in determining the actual age of an individual. They are based mainly on the different stages of calcification and are less influenced by external environmental factors ${ }^{9-11}$.

The Demirjian method consists of 8 stages $(\mathrm{A}-\mathrm{H})$. The first $4(\mathrm{~A}-\mathrm{D})$ refer to the formation of the crown. The following stages $(\mathrm{E}-\mathrm{H})$ range from the beginning of root formation to apical closure ${ }^{12}$. This method tends to overestimate the actual age of individuals ${ }^{13-15}$, with a similar mean in men $(0.65$ years $)$ and women $(0.60 \text { years })^{16}$. Intra- and inter-examiner concordance is good ${ }^{1,17}$, which implies that it can be used by the scientific community to determine the age of individuals. The Cameriere method also uses X-rays. A numerical value is obtained by dividing the sum of the widths of the intern margin of the two open apices by the length of the tooth ${ }^{18}$. Several studies have shown high precision with this method, which is between 72.4 and $75.6 \%$ for women ${ }^{19}$ and

\footnotetext{
${ }^{1}$ Department of Stomatology, Faculty of Medicine and Dentistry, Universitat de València, Valencia, Spain. ${ }^{2}$ Department of Surgery and Medical-Surgical Specialities, Area of Orthodontics, Instituto Asturiano de Odontología, University Medical and Dental School, University of Oviedo (Spain), Oviedo, Spain. ${ }^{3}$ Department of Dentistry, Faculty of Health Sciences, Universidad Europea de Valencia, Valencia, Spain. ${ }^{4}$ Public Dental Health Service, Conselleria de Sanitat Universal i Salut Pública, Generalitat Valenciana, Valencia, Spain. ${ }^{5}$ School of Dentistry, Complutense University of Madrid, Madrid, Spain. ${ }^{6}$ Public Dental Health Service, Department of Hospital, Universitario y Politécnico La Fe, Avda. Fernando Abril Martorell, 106, 46026 Valencia, Spain. ${ }^{\circledR}$ email: javiataali@gmail.com
} 


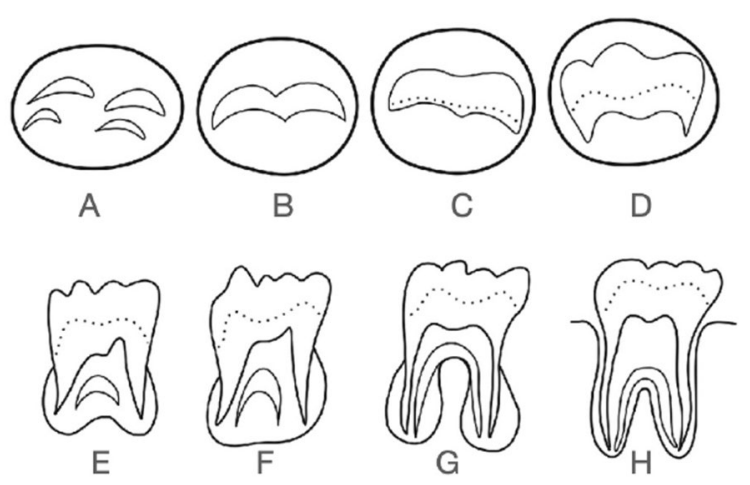

Figure 1. Representation of Demirjian method.

94.5-97.6\% for men ${ }^{20,21}$. The lowest precision value was found in a study by Deitos et al., with a value of $67.2 \%$ in men less than 18 years of age $\mathrm{e}^{22}$.

There is no method for accurately knowing the actual biological age of an individual ${ }^{23}$. Timmins et al. ${ }^{24}$ state that to know the age of individuals who are supposedly between the ages of 7 and 16, the ideal scenario would be to perform the Demirjian and Cameriere methods and a study of cervical vertebrae maturation together. On the other hand, Galic et al. ${ }^{25}$ argue that the Cameriere method is the most accurate for determining age in individuals between 6 and 13 years old.

The wisdom teeth are the last teeth to initiate and complete development ${ }^{26}$ and are also the last morphological trait, useful to determine the age of an individual and determine the majority legal age in different countries. For example, the minimum age of criminal responsibility is 14 (Venezuela, Colombia), 16 (Argentina), or 18 (Spain, Brazil, Ecuador). In addition, the minimum age for sexual consent, marriage, or access to a job varies across different countries of the world ${ }^{27}$. According to different studies, the stage of the wisdom teeth can indicate, with sufficient precision, the probability that a person is at least 18 years old. Several studies have determined the relationship between the development of wisdom teeth and chronological age ${ }^{28-30}$. Marrero-Ramos et al. ${ }^{28}$ conducted a study on a sample of 180 patients with a mean age of 21.6 years and claimed that the Demirjian method, applied to the wisdom teeth, is necessary to determine whether an individual has reached 18 years or more, and presents high inter-examiner agreement. A study by Mwesigwa et al. ${ }^{29}$ on 1021 patients in Uganda, also confirmed that this is a valid method for determining age between 10 and 22 years. On the other hand, several authors determined that the Cameriere method applied to the wisdom teeth was valid for determining 18 years of age in different populations in the Dominican Republic ${ }^{30}$, Brazil $^{31}$, Japan ${ }^{32}$, or Sardinia ${ }^{33}$. The degree of mineralisation of the wisdom teeth depends on and is specific to the studied population ${ }^{34}$.

There are very few studies that assess age determination in the Spanish population ${ }^{35}$ by means of the mineralisation stages of the wisdom teeth. The aim of the study is to determine the validity of Demirjian and Cameriere methods to predict the ages of individuals in Spanish population.

\section{Methods}

A retrospective study of 1386 panoramic X-rays from Spanish patients between 10 and 26 years of age (636 men and 750 women) was carried out.

All patients underwent a panoramic X-ray study, as clinically indicated, at the dental clinic of the University of Valencia (Valencia, Spain) between 2010 and 2016. Informed consent was obtained from all subjects. In case of minors, it was obtained from a parent and/or legal guardian. An Orthopantomograph P100 (Instrumentarium Dental, Tuusula, Finland) was used for the X-rays. X-rays were randomly selected. An initial evaluation revealed that all the wisdom teeth were present in the X-rays ${ }^{36}$ and that they were of sufficient quality for the study. Radiographs of patients with chronic diseases, genetic alterations, signs of malnutrition, or of non-ASA-I status were excluded, along with those who did not meet the above inclusion criteria. The study was conducted in accordance with the declaration of Helsinki and was approved by the institutional review board of the University of Valencia (H1422858921172).

The actual age of the individuals was calculated based on the date of birth on official documents and the time the X-ray was performed. The degree of development and mineralisation was collected with the Demirjian ${ }^{12}$ and Cameriere methods ${ }^{37}$. In the first method, each wisdom tooth was assigned a stage from $\mathrm{A}$ to $\mathrm{H}$ as follows: (A) First calcifications in the upper crypt portion. The calcification points are not fused. (B) Fusion of the calcification points forming one or more cusps. (C) Enamel formation on the occlusal surface, and beginning of dentin deposition. The pulp chamber has a curved shape in the occlusal margin. (D) Formation of the complete crown up to the cementoenamel junction. The upper part of the pulp chamber is curved in single rooted teeth and trapezoidal in multirooted teeth. Root formation begins. (E) Crown length is less than coronal height. The formation of a furcation in a semilunar form is observed, and the root length remains smaller than the coronal length. (F) The calcified furcal area is funnel-shaped and the length of the root is equal to or greater than that of the crown. $(\mathrm{G})$ The walls of the root canal are parallel, and the apex is partially open. $(\mathrm{H})$ The apex is completely closed. This method is represented in Fig. 1. The Cameriere method obtains a numerical value by dividing the 


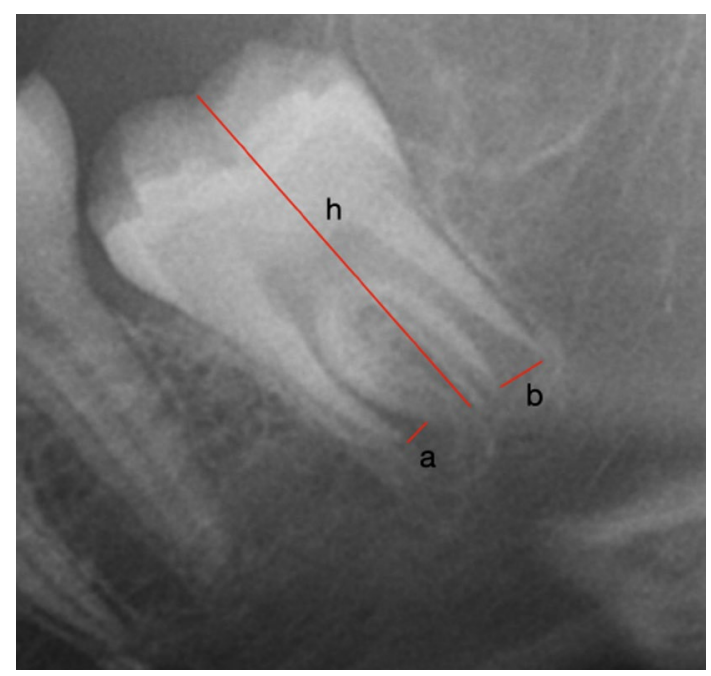

Figure 2. Representation of Cameriere method. The numerical value is obtained with the formula $(a+b) / h$.

sum of the widths of the internal margins of the open apices of that tooth by the length of the tooth, as it is explained in Fig. 2.

One observer (MM) performed observations, measurements, and data collection using both methods mentioned above. A second X-ray evaluation was performed 6 to 8 weeks after the first one to determine the intraexaminer reproducibility of each method. The observer was blinded to this second evaluation and was unaware of the previous record. After evaluating its reproducibility, the Cameriere method was used to calculate a single value based on the mean of the two measurements made, if a difference greater than 0.5 did not exist between them. If there were discrepancies between the two evaluations with the Demirjian method, the radiographs were re-evaluated along with a second observer (JAA) and the value or stage to be assigned in that case was determined.

The inferential analysis included: the t-test of independent measures (to compare the mean age of men and women with the same stage of maturation); the 1-way ANOVA F-test (to compare the mean age on 4-molar assessment in subjects of the same sex); and the Mann-Whitney test (to compare the distribution of maturation grades in men and women of the same age group). Simple linear regression analyses were established to explain and predict age, based on maturation status. Their predictive ability was assessed in terms of $\mathrm{R}^{2}$. The ages considered critical were 14, 16 and 18 years. To assess whether the degree of maturation of the third molar was a reliable parameter to establish age, a linear regression model was performed for each tooth. Kappa coefficient was used to assess intra and inter examiners' reproducibility. The SPSS version 20.0 statistical package (Chicago, IL, USA) was used for statistical analysis. The level of significance used in the analyses was $5 \%(\alpha=0.05)$, with a power of $96.2 \%$.

Ethics approval. The study was conducted in accordance with the declaration of Helsinki and was approved by the institutional review board of the University of Valencia (H1422858921172).

\section{Results}

The sample consists of 1386 subjects. The age and sex distribution of the total sample are described in Table 1.

The sample comprised of individuals between 10 and 26 years of age, with a mean age of 16.5 years (Table 2).

The intra-examiner reproducibility is higher for Demirjian (0.875) than Cameriere method (0.81). The interexaminer reproducibility is 0.79 .

The mean ages of mineralisation in various stages in the third molar, with their standard deviations and standard errors, are described in Table 3.

The differences of the mean age for a certain Demirjian maturation state according to sex were punctual. The predictive capacity of the Demirjian method for both men and women was set at $97.5 \%$ for all age ranges.

With respect to tooth 28 and stage $B$, the mean age of the men (11.4 years) was significantly lower than that of the women ( 11.8 years) $(\mathrm{p}<0.001)$. For stage $\mathrm{C}$, the mean age of the men $(13.2$ years) was significantly higher than that of the women (13.0 years) $(\mathrm{p}=0.01)$. For stage $\mathrm{D}$, the mean age of the men (15.2 years) was significantly higher than that of the women $(14.7$ years $)(p<0.001)$. For tooth 38 and stage $C$, the mean age of men and women was lower, 13.8 and 13.71 respectively $(\mathrm{p}=0.011)$. For tooth 48 and stage $\mathrm{C}$, the mean age of the men $(14.2$ years $)$ was significantly lower than that of the women $(14.7$ years $)(p=0.011)$. For stage $D$, the mean age of the men (16 years) was significantly higher than that of the women (15.7 years) $(p=0.042)$.

In both sexes, the four teeth in the same maturation states do not correspond to individuals of the same age $(\mathrm{p}<0.001)$. The only exception is stage $\mathrm{H}(\mathrm{p}>0.05)$.

The assessment of the degree of maturation in men and women at a certain age is shown in Table 4, indicating that the rate of maturation is more advanced in women. 


\begin{tabular}{|c|c|c|c|c|c|c|}
\hline & \multicolumn{6}{|l|}{ Sex } \\
\hline & \multicolumn{2}{|l|}{ Total } & \multicolumn{2}{|c|}{ Men } & \multicolumn{2}{|c|}{ Women } \\
\hline & $\mathrm{N}$ & $\%$ & $\mathbf{N}$ & $\%$ & $\mathbf{N}$ & $\%$ \\
\hline Total & 1386 & 100 & 636 & 100 & 750 & 100 \\
\hline 10 years & 103 & 7.4 & 47 & 7.4 & 56 & 7.5 \\
\hline 11 years & 102 & 7.4 & 48 & 7.5 & 54 & 7.2 \\
\hline 12 years & 146 & 10.5 & 64 & \begin{tabular}{|l|}
10.1 \\
\end{tabular} & 82 & \begin{tabular}{|l|}
10.9 \\
\end{tabular} \\
\hline 13 years & 110 & 7.9 & 48 & 7.5 & 62 & 8.3 \\
\hline 14 years & 88 & 6.3 & 46 & 7.2 & 42 & 5.6 \\
\hline 15 years & 90 & 6.5 & 54 & 8.5 & 36 & \begin{tabular}{|l}
4.8 \\
\end{tabular} \\
\hline 16 years & 108 & 7.8 & 40 & 6.3 & 68 & 9.1 \\
\hline 17 years & 108 & 7.8 & 48 & 7.5 & 60 & 8.0 \\
\hline 18 years & 105 & 7.6 & 50 & 7.9 & 55 & \begin{tabular}{|l|}
7.3 \\
\end{tabular} \\
\hline 19 years & 125 & 9.0 & 61 & 9.6 & 64 & 8.5 \\
\hline 20 yars & 82 & 5.9 & 47 & 7.4 & 35 & 4.7 \\
\hline 21 years & 91 & 6.6 & 30 & 4.7 & 61 & 8.1 \\
\hline 22 years & 35 & 2.5 & 11 & 1.7 & 24 & 3.2 \\
\hline 23 years & 30 & 2.2 & 15 & 2.4 & 15 & 2.0 \\
\hline 24 years & 31 & 2.2 & 15 & 2.4 & 16 & 2.1 \\
\hline 25 years & 32 & 2.3 & 12 & 1.9 & 20 & 2.7 \\
\hline
\end{tabular}

Table 1. Age and sex distribution of the total sample.

\begin{tabular}{|l|l|l|l|}
\hline \multirow{2}{*}{} & \multicolumn{3}{l|}{ Sex } \\
\cline { 2 - 4 } & Total & Man & Woman \\
\hline $\mathrm{N}$ & 1386 & 636 & 750 \\
\hline Mean & 16.51 & 16.42 & 16.58 \\
\hline Standard deviation & 4.05 & 3.96 & 4.12 \\
\hline Minimum & 10.00 & 10.00 & 10.00 \\
\hline Maximum & 25.70 & 25.70 & 25.60 \\
\hline Median & 16.50 & 16.30 & 16.50 \\
\hline
\end{tabular}

Table 2. Age (years) according to sex.

\begin{tabular}{|c|c|c|c|c|c|c|c|c|c|c|c|c|c|c|c|c|c|c|}
\hline \multirow{3}{*}{\multicolumn{3}{|c|}{ Demijian stages }} & \multicolumn{16}{|l|}{ Age } \\
\hline & & & \multicolumn{2}{|l|}{ A } & \multicolumn{2}{|l|}{ B } & \multicolumn{2}{|l|}{$\mathrm{C}$} & \multicolumn{2}{|l|}{ D } & \multicolumn{2}{|l|}{$\mathbf{E}$} & \multicolumn{2}{|l|}{$F$} & \multicolumn{2}{|l|}{ G } & \multicolumn{2}{|l|}{$\mathbf{H}$} \\
\hline & & & Mean & SD & Mean & SD & Mean & SD & Mean & SD & Mean & SD & Mean & SD & Mean & SD & Mean & SD \\
\hline \multirow{8}{*}{ Sex } & \multirow{4}{*}{ Men } & DEM 18 & 10.51 & 0.41 & 11.56 & 0.52 & 12.97 & 0.74 & 14.18 & 0.79 & 16.01 & 0.78 & 17.86 & 0.87 & 19.04 & 1.25 & 22.17 & 1.94 \\
\hline & & DEM 28 & 10.69 & 0.59 & 11.41 & 0.65 & 13.25 & 0.74 & 15.23 & 0.75 & 16.54 & 0.87 & 18.01 & 0.97 & 19.27 & 0.98 & 22.34 & 1.85 \\
\hline & & DEM 38 & 11.01 & 0.70 & 12.28 & 0.83 & 13.80 & 0.87 & 15.67 & 0.83 & 17.49 & 0.97 & 18.43 & 0.97 & 19.93 & 0.76 & 22.39 & 1.87 \\
\hline & & DEM 48 & 11.15 & 0.73 & 12.63 & 0.89 & 14.15 & 1.29 & 15.96 & 0.86 & 17.69 & 0.99 & 18.63 & 0.87 & 20.29 & 0.79 & 22.57 & 1.91 \\
\hline & \multirow{4}{*}{ Women } & DEM 18 & 10.38 & 0.46 & 11.62 & 0.71 & 12.85 & 0.51 & 14.20 & 0.60 & 15.94 & 0.90 & 17.64 & 1.01 & 19.06 & 1.32 & 22.12 & 1.83 \\
\hline & & DEM 28 & 10.87 & 0.3 & 11.83 & 0.89 & 13.01 & 0.52 & 14.73 & 0.82 & 16.33 & \begin{tabular}{|l|}
0.81 \\
\end{tabular} & \begin{tabular}{|l|}
18.12 \\
\end{tabular} & 1.09 & 19.34 & 1.22 & 22.18 & 1.79 \\
\hline & & DEM 38 & 11.15 & 0.89 & 12.32 & \begin{tabular}{|l|l|}
0.79 \\
\end{tabular} & 13.71 & 0.95 & 15.53 & \begin{tabular}{|l|l|}
0.94 \\
\end{tabular} & 17.28 & \begin{tabular}{|l|}
0.97 \\
\end{tabular} & 18.52 & 1.01 & 20.09 & 0.99 & 22.51 & 1.68 \\
\hline & & DEM 48 & 11.25 & 0.93 & 12.52 & 0.80 & 14.71 & 1.40 & 15.68 & \begin{tabular}{|l|}
0.97 \\
\end{tabular} & 17.91 & \begin{tabular}{|l|}
0.99 \\
\end{tabular} & 18.54 & 1.01 & 20.15 & 1.00 & 22.51 & 1.69 \\
\hline
\end{tabular}

Table 3. Age according to Demirjian dental status by sex. $S D$ standard deviation.

In men, a subject is more than 14 years of age, if presenting with at least stage E. Similarly, subjects may be more than 16 years of age with a probability of $97.5 \%$ if presenting with at least stage $\mathrm{F}$, and more than 18 if presenting with stage $\mathrm{H}$ for tooth 18 (all of them with a probability of $97.5 \%$ ). The same data are obtained for tooth 28 , with a $94.2 \%$ probability. Stage G determines the critical age of 18 years in tooth 38 , with a certainty of $93.6 \%$. The critical age of 14 years is determined by stage D in tooth 48 , with a $92.1 \%$ probability. The other stages are kept the same. 


\begin{tabular}{|c|c|c|c|c|}
\hline & \begin{tabular}{|l|} 
Tooth 18 \\
\end{tabular} & \begin{tabular}{|l|} 
Tooth 28 \\
\end{tabular} & \begin{tabular}{|l|} 
Tooth 38 \\
\end{tabular} & \begin{tabular}{|l|} 
Tooth 48 \\
\end{tabular} \\
\hline 10 years & 0.919 & $0.009^{\star *}$ & 0.867 & 0.581 \\
\hline 11 years & 0.493 & 0.124 & 0.662 & 0.882 \\
\hline 12 years & $0.043^{*}$ & $0.003^{* *}$ & $0.004^{\star *}$ & $0.036^{*}$ \\
\hline 13 years & 0.563 & 0.845 & $0.046^{\star}$ & 0.744 \\
\hline 14 years & $<0.001^{* * *}$ & $<0.001^{\star * *}$ & $<0.001^{* * *}$ & $<0.001^{\star * *}$ \\
\hline 15 years & 0.955 & 0.540 & 0.861 & 0.536 \\
\hline 16 years & 0.196 & $0.003^{* *}$ & 0.945 & 0.650 \\
\hline 17 years & 0.083 & 0.341 & 0.059 & 0.325 \\
\hline 18 years & $0.015^{*}$ & 0.655 & $<0.001^{* * *}$ & $0.010^{*}$ \\
\hline 19 years & $0.008^{* *}$ & $<0.001^{* * *}$ & $<0.001^{* * *}$ & $<0.001^{* * *}$ \\
\hline 20 years & $<0.001^{* * *}$ & $<0.001^{* * *}$ & 0.122 & 0.055 \\
\hline 21 years & 0.603 & 0.603 & 0.603 & $0.010^{*}$ \\
\hline 22 years & 1.000 & 1.000 & 1.000 & 1.000 \\
\hline 23 years & 1.000 & 1.000 & 1.000 & 1.000 \\
\hline 24 years & 1.000 & 1.000 & 1.000 & 1.000 \\
\hline 25 years & 1.000 & 1.000 & 1.000 & 1.000 \\
\hline
\end{tabular}

Table 4. Grade of maturation in men and women, according to Demirjian method. ${ }^{\star} \mathrm{p}<0.05 ;{ }^{* *} \mathrm{p}<0.01$; ${ }^{* * *} \mathrm{p}<0.001$.

\begin{tabular}{|l|l|l|l|l|l|}
\hline & Tooth 18 (stage G) & Tooth 28 (stage G) & Tooth 38 (stage F) & Tooth 48 (stage F) & All \\
\hline Sensitivity & $85.7-85.3$ & $83.1-76.2$ & $90.0-93.7$ & $88.7-86.4$ & $99.1-93.7$ \\
\hline Specificity & $94.8-96.1$ & $96.8-97.8$ & $93.3-94.8$ & $95.3-96.1$ & $90.1-94.8$ \\
\hline PPV & $90.4-93.1$ & $93.7-95.6$ & $88.5-91.8$ & $91.5-93.2$ & $85.1-91.8$ \\
\hline PNV & $92.1-91.4$ & $91.0-87.0$ & $94.3-96.1$ & $93.7-92.0$ & $99.5-96.1$ \\
\hline Correct totals & $91.5-92.0$ & $91.8-89.6$ & $92.1-94.4$ & $92.9-92.4$ & $93.4-94.4$ \\
\hline
\end{tabular}

Table 5. Predictive validity (\%) of the Demijiran stages for predicting age over 18 years in men-women.

Women are more than 14 years of age if presenting with at least stage E. They are more than 16 years of age if presenting with at least stage $\mathrm{G}$ and more than 18 years of age if they present a stage $\mathrm{H}$ for tooth 18 (all of them with a probability of $97.5 \%$ ). In teeth 28,38 and 48 , the stages of maturation that indicate 16 and 18 years are maintained, with stage $\mathrm{E}$ being the one that marks 14 years.

To verify the predictive validity of the Demirjian method for the prediction of age $\geq 18$ years, contingency tables were made for all wisdom teeth in men and women (Table 5). The prediction rule establishes that, for 18 and 28, Demirjian stage $\geq G$ indicates that the subject is over 18 years old. For 38 and 48 , the critical stage is $F$.

According to the Cameriere method, the mean age of men (21.6 years) was significantly lower than that of women (22.0 years) for tooth 38 in the range of $0-0.04$. In the range of $0.08-0.3$, this interpretation is reversed. The mean age of men (18.1 years) was significantly higher than that of women (17.8 years). For tooth 48 , no relevant difference was detected.

According to the same method, the rate of maturation was more advanced in women. For 14 years and in tooth $48,4.3 \%$ men had a Cameriere value of 0.9 or less, but the percentage rose to $19.1 \%$ for women of that age. Women presented more maturation at the age of 18 . Only in certain age range is it observed that the maturity range is significantly different between men and women.

To verify the predictive validity of the Cameriere cut-off of 0.08 for the prediction of age $\geq 18$ years presented by some authors, some contingency tables were made for teeth 38 and 48 in men and women. The total value obtained is more than $92 \%$ in men and $95 \%$ in women (Table 6).

The combination of both methods raises predictability to above $94 \%$ in all cases, so the gain is not statistically significant.

\section{Discussion}

Various methods have been proposed for estimating the actual age of an individual based on the maturation of the third molar ${ }^{10,12,38}$. The importance of knowing the stage of maturation in the wisdom teeth lies in the fact that they are the only teeth whose roots continue to develop after 16 years of age ${ }^{39}$. The Demirjian method is proposed as a simple, reproducible, and highly concordant method within and between examiners ${ }^{40}$. On the other hand, the Cameriere method is highly precise ${ }^{41}$, and so it was considered interesting to carry out a study to estimate the real age of a Spanish population with these methods, with special emphasis on 18 years of age, the legal age in our country. 


\begin{tabular}{|l|c|l|}
\hline & Tooth 38 & Tooth 48 \\
\hline Sensitivity & $79.7-90.0$ & $82.6-90.3$ \\
\hline Specificity & $100-100$ & $99.5-98.9$ \\
\hline PPV & $100-100$ & $99.0-98.1$ \\
\hline PNV & $89.0-93.5$ & $90.3-94.2$ \\
\hline Correct totals & $92.3-95.7$ & $93.1-95.6$ \\
\hline
\end{tabular}

Table 6. Predictive validity $(\%)$ of the Cameriere criterion $(<0.08)$ for predicting age over 18 years in menwomen.

Numerous studies have evaluated differences in calcification associated with sex and race with the Demirjian ${ }^{9,36,42,43}$ and Cameriere methods ${ }^{44,45}$. In the paper presented by Qing et al. ${ }^{36}$, no statistically significant differences were observed between men and women, except for tooth 48 in stage E that occurred earlier in women. Sisman et al. ${ }^{9}$ analysed a population of 900 Turkish individuals, where a statistically significant difference between sexes was present in stages D and G, with maturation occurring earlier in men than in women. In contrast, in our study, the mean age of men was higher than that of women in all stages except for tooth 48 and stage $C$, where the mean age of men (14.2 years) was significantly lower than that of women (14.7 years) $(\mathrm{p}=0.011)$. Thus, women have the fastest degree of maturation, as observed in other published studies. Rai et al. $^{46}$, in their work on individuals in northern India, found statistically significant differences in stages D and $\mathrm{G}$, stating that third molar formation occurred earlier in women. Another published study states that stages $\mathrm{F}$ to $\mathrm{H}$ in the maxilla and stages $\mathrm{A}$ and $\mathrm{E}$ in the jaw occur in the same manner ${ }^{47}$. Hofmann et al. ${ }^{34}$ observed that stage $\mathrm{C}$ mineralisation occurred earlier in women than in men $(\mathrm{p}=0.024)$, although the age difference was very small. Other studies found no statistically significant differences between sexes with the Demirjian method regarding third molar maturation ${ }^{48,49}$.

According to the results derived from our study, women have earlier third molar maturation than men, with the Cameriere method. This result agrees with other publications ${ }^{50}$. However, other authors found earlier mineralisation in men rather than in women ${ }^{44,45}$. However, in some cases, significant differences only occurred in the mean ages with a value $\geq 0.08$, except for those ranging from 0.7 to $0.9^{22}$. Finally, it should be noted that other authors found no differences between sexes regarding the development of the third molar ${ }^{51}$.

Stage $\mathrm{H}$ has been considered a key factor in numerous studies for determining 18 years of age. These results coincide with those obtained in our study, although in the case of tooth 38 , it is stage G that establishes 18 years of age. The presence of stage $\mathrm{H}$ in the third molars indicates an older individual in countries such as Spain or Brazil according to different authors ${ }^{52}$. However, Roberts et al. ${ }^{53}$ state that these results are not entirely reliable since the mean age obtained in them is too broad. For stage $H$, the mean age was 17.9 years in a study by Soares et al. ${ }^{54}$.

For its part, the cut-off point of 0.08 could be decisive in determining older and younger individuals based on the results obtained from our study, by using the Cameriere method. This data coincides with that published by other authors such as Ribier et al..$^{4}$, who carried out their work in a French population. Galic et al. ${ }^{18}$ conducted their study in a Croatian population, concluding that in those with values below $0.08,94.5 \%$ of women and $96.5 \%$ of men were 18 years or older; therefore, this index can be used with high precision in the studied population. Khare et al. ${ }^{45}$ also consider this to be a valid method for differentiating between minors and adults in the Chinese population, with a cut-off point of 0.08 . The same result was obtained by Tafrount et al. ${ }^{55}$ in a population from south-eastern France and by Palmela-Pereira et al. ${ }^{56}$ and Albernaz et al. ${ }^{57}$ in the Portuguese population.

\section{Conclusions}

The predictive capacity of $97.5 \%$ of the Demirjian method and of up to $95 \%$ with the Cameriere method helps determine the actual age of individuals, considering that we have managed to establish values for the studied ages. Stage $\mathrm{H}$ and cut-off point of 0.08 are useful in estimating age above 18 for men and women in Spanish population.

\section{Data availability}

The datasets used and/or analyzed during the current study are available from the corresponding author on reasonable request.

Received: 14 September 2021; Accepted: 8 February 2022

Published online: 18 February 2022

\section{References}

1. Melo, M. \& Ata-Ali, J. Accuracy of the estimation of dental age in comparison with chronological age in a Spanish sample of 2641 living subjects using the Demirjian and Nolla methods. Forensic Sci. Int. 270, e1-e7 (2017).

2. Al Qattan, F. et al. Root pulp visibility as a mandibular maturity marker at the 18 -year threshold in the Maltese population. Int. J. Legal Med. 134, 363-368 (2020).

3. Ata-Ali, J. \& Ata-Ali, F. Forensic dentistry in human identification: A review of the literature. J. Clin. Exp. Dent. 6, e162-167 (2014).

4. Fishman, L. S. Radiographic evaluation of skeletal maturation. A clinically oriented method based on hand-wrist films. Angle Orthod. 52, 88-112 (1982).

5. Björk, A. \& Helm, S. Prediction of the age of maximum puberal growth in body height. Angle Orthod. 37, 134-143 (1967).

6. Baccetti, T., Franchi, L. \& McNamara, J. A. Reproducibility of the CVM method: A reply. Am. J. Orthod. Dentofacial Orthop. 137, 446-447 (2010). 
7. Oliveira, L. B., Turssi, C. P. \& Junqueira, J. L. Validity of the assessment method of skeletal maturation by cervical vertebrae: A systematic review and meta-analysis. Dentomaxillofac. Radiol. 46, 20160370 (2017).

8. Cericato, G. O., Bittencourt, M. A. \& Paranhos, L. R. Validity of the assessment method of skeletal maturation by cervical vertebrae: A systematic review and meta-analysis. Dentomaxillofac. Radiol. 44, 20140270 (2015).

9. Sisman, Y., Uysal, T., Yagmur, F. \& Ramoglu, S. I. Third-molar development in relation to chronologic age in Turkish children and young adults. Angle Orthod. 77, 1040-1045 (2007).

10. Cameriere, R., Flores-Mir, C., Mauricio, F. \& Ferrante, L. Effects of nutrition on timing of mineralization in teeth in a Peruvian sample by the Cameriere and Demirjian methods. Ann. Hum. Biol. 34, 547-556 (2007).

11. Kutesa, A. M. et al. Socioeconomic and nutritional factors associated with age of eruption of third molar tooth among Ugandan adolescents. J. Forensic Dent. Sci. 11, 22-27 (2019).

12. Demirjian, A., Goldstein, H. \& Tanner, J. M. A new system of dental age assessment. Hum. Biol. 45, 211-227 (1973).

13. Khorate, M. M., Dinkar, A. D. \& Ahmed, J. Accuracy of age estimation methods from orthopantomograph in forensic odontology: A comparative study. Forensic Sci. Int. 234, e1-e8 (2014).

14. Flood, S. J., Franklin, D., Turlach, B. A. \& McGeachie, J. A comparison of Demirjian’s four dental development methods for forensic age estimation in South Australian sub-adults. J. Forensic Leg Med. 20, 875-883 (2013).

15. Feijóo, G., Barbería, E., De Nova, J. \& Prieto, J. L. Dental age estimation in Spanish children. Forensic Sci. Int. 22, e1-e5 (2012).

16. Jayaraman, J., Wong, H. M., King, N. M. \& Roberts, G. J. The French-Canadian data set of Demirjian for dental age estimation: A systematic review and meta-analysis. J. Forensic Leg Med. 20, 373-381 (2013).

17. Eid, R. M., Simi, R., Friggi, M. N. \& Fisberg, M. Assessment of dental maturity of Brazilian children aged 6 to 14 years using Demirjian's method. Int. J. Paediatr. Dent. 12, 423-428 (2002).

18. Galić, I. et al. Cameriere’s third molar maturity index in assessing age of majority. Forensic Sci. Int. 252, e1-e5 (2015).

19. AlQahtani, S., Kawthar, A., AlAraik, A. \& AlShalan, A. Third molar cut-off value in assessing the legal age of 18 in Saudi population. Forensic Sci. Int. 272, 64-67 (2017).

20. Dardouri, A. A. K., Cameriere, R., De Luca, S. \& Vanin, S. Third molar maturity index by measurements of open apices in a Libyan sample of living subjects. Forensic Sci. Int. 267, e1-e6 (2016).

21. Gulsahi, A., De Luca, S., Cehreli, S. B., Tirali, R. E. \& Cameriere, R. Accuracy of the third molar index for assessing the legal majority of 18 years in Turkish population. Forensic Sci. Int. 266, e1-e6 (2016).

22. Deitos, A. R. et al. Age estimation among Brazilians: Younger or older than 18? J. Forensic Leg Med. 33, 111-115 (2015).

23. Kirschneck, C. \& Proff, P. Age assessment in orthodontics and general dentistry. Quintessence Int. 49, 313-323 (2018).

24. Timmins, K., Liversidge, H., Farella, M., Herbison, P. \& Kieser, J. The usefulness of dental and cervical maturation stages in New Zealand children for disaster victim identification. Forensic Sci. Med. Pathol. 8, 101-108 (2012).

25. Galić, I. et al. Accuracy of Cameriere, Haavikko, and Willems radiographic methods on age estimation on Bosnian-Herzegovian children age groups 6-13. Int. J. Legal Med. 125, 315-321 (2011).

26. Van Vlierberghe, M. et al. A comparative study of two different regression methods for radiographs in Polish youngsters estimating chronological age on third molars. Forensic Sci. Int. 201, 86-94 (2010).

27. Lacro, U. Legal Minimum Ages and the Realization of Adolescents' Rights, 5-8 (2017).

28. Marrero-Ramos, M. D., López-Urquía, L., Suárez-Soto, A., Sánchez-Villegas, A. \& Vicente-Barrero, M. Estimation of the age of majority through radiographic evaluation of the third molar maturation degree. Med. Oral. Patol. Oral Cir. Bucal. 25, e359-e363 (2020).

29. Mwesigwa, C. L., Kutesa, A. M., Munabi, I. G., Kabenge, C. A. \& Buwembo, W. Accuracy of the lower third molar radiographic imaging to estimate age among Ugandan young people. BMC Res. Notes 12, 652 (2019).

30. Gómez Jiménez, L. et al. Validation of the third molar maturity index (I3M): Study of a Dominican Republic sample. J. Forensic Odontostomatol. 3, 27-33 (2019).

31. Nóbrega, J. B. et al. Validation of the third molar maturation index to estimate the age of criminal responsibility in Northeastern Brazil. Forensic Sci Int. 304, 109917 (2019).

32. Kumagai, A. et al. Accuracy of the third molar index cut-off value for estimating 18 years of age: Validation in a Japanese sample. Leg Med. (Tokyo) 38, 5-9 (2019).

33. Spinas, E., De Luca, S., Lampis, L., Velandia Palacio, L. A. \& Cameriere, R. Is the third molar maturity index (I3M) useful for a genetic isolate population? Study of a Sardinian sample of children and young adults. Int. J. Legal Med. 132, 1787-1794 (2018).

34. Hofmann, E., Robold, M., Proff, P. \& Kirschneck, C. Age assessment based on third molar mineralisation: An epidemiologicalradiological study on a Central-European population. J. Orofac. Orthop. 78, 97-111 (2017).

35. Prieto, J. L., Barbería, E., Ortega, R. \& Magaña, C. Evaluation of chronological age based on third molar development in the Spanish population. Int. J. Legal Med. 119, 349-354 (2005).

36. Qing, M., Qiu, L., Gao, Z. \& Bhandari, K. The chronological age estimation of third molar mineralization of Han population in southwestern China. J. Forensic Leg Med. 24, 24-27 (2014).

37. Cameriere, R., Ferrante, L., De Angelis, D., Scarpino, F. \& Galli, F. The comparison between measurement of open apices of third molars and Demirjian stages to test chronological age of over 18 year olds in living subjects. Int. J. Legal Med. 122, 493-497 (2008).

38. Ann, S. The accuracy and precision of third molar development as an indicator of chronological age in Hispanics. J. Forensic Sci. 47, 531-535 (2002).

39. Maled, V. \& Vishwanath, S. B. The chronology of third molar mineralization by digital orthopantomography. J Forensic Leg Med. 43, 70-75 (2016).

40. Dhanjal, K. S., Bhardwaj, M. K. \& Liversidge, H. M. Reproducibility of radiographic stage assessment of third molars. Forensic Sci. Int. 159, S74-77 (2006).

41. Cameriere, R. et al. Assessment of legal adult age of 18 by measurement of open apices of the third molars: Study on the Albanian sample. Forensic Sci. Int. 245, e1-e5 (2014).

42. Martin-de las Heras, S., García-Fortea, P., Ortega, A., Zodocovich, S. \& Valenzuela, A. Third molar development according to chronological age in populations from Spanish and Magrebian origin. Forensic Sci. Int. 174, 47-53 (2008).

43. Olze, A. et al. Validation of common classification systems for assessing the mineralization of third molars. Int. J. Legal Med. 119, $22-26$ (2005).

44. Ribier, L. et al. Cameriere's third molar maturity index in assessing age of majority: A study of a French sample. Int. J. Legal Med. 134, 783-792 (2020).

45. Khare, P. et al. Validation of the third molar maturity index cut-off value of $<0.08$ for indicating legal age of 18 years in Eastern Chinese region. Leg Med. 42, 101645 (2020).

46. Rai, B., Kaur, J. \& Anand, S. C. Mandibular third molar development staging to chronologic age and sex in north Indian children and young adults. J. Forensic Odontostomatol. 27, 45-49 (2009).

47. Ashifa, N., Parakh, M. K. \& Ulaganambi, S. Estimation of age using third molar development: A radiological cross-sectional study. Am. J. Forensic Med. Pathol. 41, 115-118 (2020).

48. Lewis, A. J. et al. Demirjian's method in the estimation of age: A study on human third molars. J. Forensic Dent. Sci. 7, 153-157 (2015).

49. Orhan, K., Ozer, L., Orhan, A. I., Dogan, S. \& Paksoy, C. S. Radiographic evaluation of third molar development in relation to chronological age among Turkish children and youth. Forensic Sci. Int. 165, 46-51 (2007). 
50. Santiago, B. M., Almeida, L., Cavalcanti, Y. W., Magno, M. B. \& Maia, L. C. Accuracy of the third molar maturity index in assessing the legal age of 18 years: A systematic review and meta-analysis. Int. J. Legal Med. 132, 1167-1184 (2018).

51. De Luca, S. et al. Accuracy of Cameriere's cut-off value for third molar in assessing 18 years of age. Forensic Sci. Int. 235, e1-e6 (2014).

52. Streckbein, P. et al. Estimation of legal age using calcification stages of third molars in living individuals. Sci. Justice 54, 447-450 (2014).

53. Roberts, G. J., McDonald, F., Andiappan, M. \& Lucas, V. S. Dental age estimation (DAE): Data management for tooth development stages including the third molar. Appropriate censoring of Stage H, the final stage of tooth development. J. Forensic Leg. Med. 36, $177-184(2015)$.

54. Soares, C. B. et al. Evaluation of third molar development in the estimation of chronological age. Forensic Sci. Int. 254, 13-17 (2015).

55. Tafrount, C., Galić, I., Franchi, A., Fanton, L. \& Cameriere, R. Third molar maturity index for indicating the legal adult age in southeastern France. Forensic Sci. Int. 294, e1-e6 (2019).

56. Palmela Pereira, C. et al. Cut-off for the legal ages in the Portuguese population by third maturity index: Measures of accuracy. Arch. Oral Biol. 125, 105089 (2021).

57. Albernaz Neves, J. et al. Validation of the third molar maturation index. Sci. Rep. 10, 18466 (2020).

\section{Author contributions}

M.M. and J.A. contributed to the study conception and design. Data collection and data analysis was performed by M.M. and F.A. Statistical analysis was done by J.A. and J.M.M. The first draft of the manuscript was written by M.M. and T.C. All authors commented on previous versions of the manuscript and all authors have read and approved the final version of the manuscript.

\section{Competing interests}

The authors declare no competing interests.

\section{Additional information}

Correspondence and requests for materials should be addressed to J.A.-A.

Reprints and permissions information is available at www.nature.com/reprints.

Publisher's note Springer Nature remains neutral with regard to jurisdictional claims in published maps and institutional affiliations.

(c) (i) Open Access This article is licensed under a Creative Commons Attribution 4.0 International License, which permits use, sharing, adaptation, distribution and reproduction in any medium or format, as long as you give appropriate credit to the original author(s) and the source, provide a link to the Creative Commons licence, and indicate if changes were made. The images or other third party material in this article are included in the article's Creative Commons licence, unless indicated otherwise in a credit line to the material. If material is not included in the article's Creative Commons licence and your intended use is not permitted by statutory regulation or exceeds the permitted use, you will need to obtain permission directly from the copyright holder. To view a copy of this licence, visit http://creativecommons.org/licenses/by/4.0/.

(c) The Author(s) 2022 